\title{
High-Pressure Synthesis of New Magnetic Compound in Mn-Li-N System
}

\author{
Itsuki Matsushita $^{1}$, Atsunori Kamegawa ${ }^{2,3,{ }^{*}}$ and Satoshi Sugimoto ${ }^{1}$ \\ ${ }^{1}$ Department of Materials Science, Graduate School of Engineering, Tohoku University, Sendai 980-8579, Japan \\ ${ }^{2}$ Muroran Institute of Technology, Muroran 050-8585, Japan \\ ${ }^{3}$ JST-PRESTO, Japan Science and Technology Agency, Tokyo 102-0076, Japan
}

\begin{abstract}
A new magnetic compound in the Mn-Li-N system was synthesized at GPa-order pressure. This compound had a body-centered-tetragonal (bct) structure (space group: $I 4 / \mathrm{mmm}$, No. 139) with lattice parameters $a=0.29186 \mathrm{~nm}$ and $c=0.39108 \mathrm{~nm}$. The compound composition ratio was $\mathrm{Mn}: \mathrm{N}=2: 1$. The saturation magnetization and coercivity of a sample synthesized under $5 \mathrm{GPa}$ at $1100^{\circ} \mathrm{C}$ for $2 \mathrm{~h}$ were $17.73 \mathrm{~A} \cdot \mathrm{m}^{2} / \mathrm{kg}$ and $310.7 \mathrm{kA} / \mathrm{m}$, respectively. [doi:10.2320/matertrans.M2016096]
\end{abstract}

(Received March 11, 2016; Accepted July 12, 2016; Published August 26, 2016)

Keywords: manganese-lithium-nitrogen system, high-pressure synthesis, magnetic material

\section{Introduction}

Mn-based magnetic compounds have attracted considerable attention as a result of their high coercivity, and because they are candidates for a variety of applications. For example, $\mathrm{MnBi}^{1)}$ and $\mathrm{Mn}-\mathrm{Al}-\mathrm{C}^{2)}$ are candidates for alternative permanent-magnet materials without critical elements, while $\mathrm{Mn}_{3} \mathrm{Ga}^{3,4)}$ and $\mathrm{Mn}_{3} \mathrm{Ge}^{5)}$ are expected to be suitable for spintorque transfer applications. Some compounds in the MnPnictogen (Pn) system, such as $\mathrm{MnBi}$, have relatively high coercive forces. Furthermoe the amplitudes of the magnetic moments in some Mn-Pn compounds are more than $3.5 \mu_{\mathrm{B}} /$ $\left.\mathrm{Mn}_{\text {atom }}{ }^{6}\right)\left(\mu_{\mathrm{B}}\right.$ is the Bohr magneton). Therefore, Mn compounds have considerable potential for application in highperformance permanent magnets, and $\mathrm{Mn}$ is regarded as a substance of interest in the search for new magnetic materials with high coercivity.

The exploration of novel magnetic compounds in an alkali metal (AM) system was focused in this study. AMs react only minimally with $3 \mathrm{~d}$-transition metals $(3 \mathrm{~d}-\mathrm{TMs})^{7)}$ and, as a result, permanent magnet alloys consisting of AMs have been only minimally reported. AMs tend to be sensitive to pressure; for example, the atomic compressibilities of these metals are significantly higher than those of transition metals ${ }^{8)}$. This difference in compressibility causes a change in the relative radii of the atoms and induces atomic rearrangement and high-pressure phases. In fact, many high-pressure phases comprised of AMs have been found. In this study, Li was selected as the AM, because of its low atomic weight, so as to prevent this component from weakening the gravimetric magnetization.

In addition, $\mathrm{N}$, which is one of the Pn elements, was selected as the third element (with $\mathrm{Li}$ and $\mathrm{Mn}$ ). Certain $\mathrm{Mn}-\mathrm{N}$ binary system compounds, i.e., $\mathrm{Mn}_{4} \mathrm{~N}, \mathrm{Mn}_{3} \mathrm{~N}_{2}, \mathrm{Mn}_{2} \mathrm{~N}_{1-\mathrm{x}}$, and $\mathrm{MnN}$, have been reported previously ${ }^{9)}$. The crystal structure of $\mathrm{Mn}_{2} \mathrm{~N}_{1-\mathrm{x}}$ is hexagonal, and differs from those of the other $\mathrm{Mn}-\mathrm{N}$ compounds. However, the $\mathrm{Mn}_{4} \mathrm{~N}, \mathrm{Mn}_{3} \mathrm{~N}_{2}$, and $\mathrm{MnN}$ crystals structures are similar to each other, having only small differences in their lattice constants, $\mathrm{N}$ content values, and $\mathrm{N}$ locations. On the other hand, only $\mathrm{Mn}_{4} \mathrm{~N}$ exhibits ferrimagne-

*Corresponding author, E-mail: kamegawa@mmm.muroran-it.ac.jp tism ${ }^{10)}$, while the other $\mathrm{Mn}-\mathrm{N}$ compounds are non-magnetic at room temperature ${ }^{11-13)}$. Therefore, the magnetism in the $\mathrm{Mn}-\mathrm{N}$ system is sensitive to either the lattice constants or the $\mathrm{N}$ content.

High-pressure synthesis is also employed in this study. This is an effective method for exploring novel compounds and materials, in which samples are heat-treated under GPa-order pressure. Many new compounds have been identified using this technique, for example, in the fields of hydrogen storage materials, superconducting materials, and thermoelectric materials ${ }^{14-16)}$. However, this method has not been applied to the search for novel magnetic materials.

The purpose of this study is to explore a new compound in the $\mathrm{Mn}-\mathrm{Li}-\mathrm{N}$ system using high-pressure synthesis, and to investigate the crystal structure and magnetic properties of the newly found compound.

\section{Experimental Procedure}

Mn (99.99-mass\% purity) and $\mathrm{LiNH}_{2}$ (95-mass\% purity) powders were used as starting materials. $\mathrm{LiNH}_{2}$ was used as a source of both $\mathrm{Li}$ and $\mathrm{N}$, because this material has significantly higher $\mathrm{N}$ content than other $\mathrm{Li}-\mathrm{N}$ based compounds. Nominal-composition powder mixtures were pressed into pellets and sealed into a high-pressure sample cell. In this cell, the samples were packed by sintered hexagonal boron nitride ( $\mathrm{h}-\mathrm{BN})$, which acted as the pressure medium. Highpressure synthesis was then conducted using a multi-cubic anvil-type apparatus. The sample cells were heated at $1100^{\circ} \mathrm{C}$ for $2 \mathrm{~h}$ under pressures of 2-6 GPa and then quenched. Note that the excess hydrogen exited through the sample cell during the synthesis reaction.

Phase identification was conducted via powder X-ray diffraction $(\mathrm{XRD})$ analysis using $\mathrm{Cu}-\mathrm{K} \alpha$ radiation. Compositional analysis was performed using an electron probe micro-analyzer (EPMA) or through scanning electron microscope/energy -dispersive X-ray analysis (SEM-EDX). The magnetic properties were investigated using a vibrating sample magnetometer (VSM). Some samples for microstructural observation were prepared using a focused ion beam (FIB) system. 


\section{Results and Discussions}

Figure 1 shows the XRD patterns of the $\mathrm{Mn}+\mathrm{LiNH}_{2}$ samples treated at $1100^{\circ} \mathrm{C}$ for $2 \mathrm{~h}$ under pressures of 2-6 GPa. The molar ratio of the $\mathrm{Mn}: \mathrm{LiNH}_{2}$ nominal composition was 1:1. Unidentified peaks were observed for all of the samples, and $\zeta$-phase $\left(\mathrm{Mn}_{2} \mathrm{~N}_{1-\mathrm{x}}\right)$ was observed in the samples subjected to pressures of 2-4 GPa. The intensities of the unidentified peaks increased with increasing applied pressure. In the sample prepared under $5 \mathrm{GPa}$ pressure (hereafter, the "5-GPa sample”), the unidentified peaks were mainly observed with small h-BN and cubic-BN (c-BN) peaks, corresponding to a diamond-type crystal structure. The unidentified peaks weakened when the applied pressure was increased to $6 \mathrm{GPa}$; however, the $\mathrm{c}-\mathrm{BN}$ peak intensities increased. Under high-pressure and high-temperature conditions, Li-based compounds such as $\mathrm{LiNH}_{2}$ are reported to act as catalysts to transform $\mathrm{h}-\mathrm{BN}$ into $\mathrm{c}-\mathrm{BN}^{17)}$. Thus, it was assumed that the $\mathrm{h}-\mathrm{BN}$ sealed in the high-pressure sample cell as a pressure medium transformed into c-BN, because of the presence of $\mathrm{LiNH}_{2}$ in the samples.

Figure 2 shows the (a) coercivities and (b) saturation magnetization of the $\mathrm{Mn}+\mathrm{LiNH}_{2}$ samples treated at $1100^{\circ} \mathrm{C}$ for $2 \mathrm{~h}$ under 2-6 GPa. Although some discrepancies are apparent in the overall trends, both the coercivity $(310.7 \mathrm{kA} / \mathrm{m})$ and saturation magnetization $\left(17.7 \mathrm{~A} \cdot \mathrm{m}^{2} / \mathrm{kg}\right)$ of the $5-\mathrm{GPa}$ sample, which was primarily comprised of the unidentified phase according to the XRD results, were higher than those of the other samples. Figure 3 shows the magnetization curve measured by VSM of the 5-GPa sample. Based on the XRD and VSM results, the unidentified phase was assumed to have high coercivity.

To determine the features of the unidentified phase, a composition analysis was conducted. Figure 4 shows (a) a back-

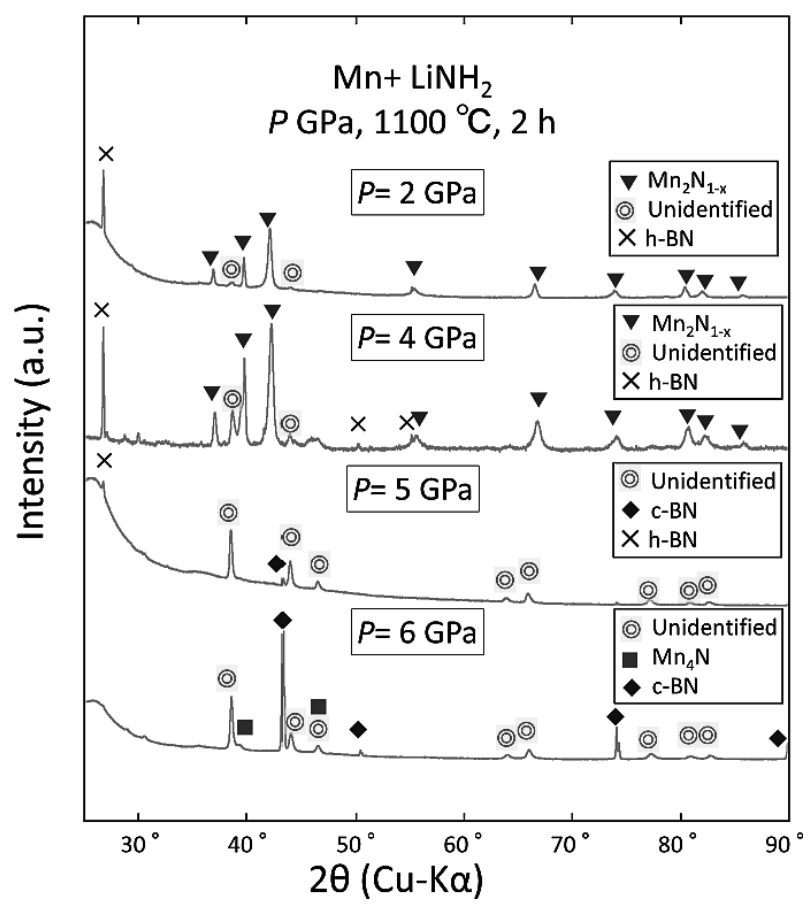

Fig. 1 XRD patterns of $\mathrm{Mn}+\mathrm{LiNH}_{2}$ samples treated at $1100^{\circ} \mathrm{C}$ for $2 \mathrm{~h}$ under pressure $P=2-6$ scattered electron (BSE) image and (b)-(d) Mn, N, and B element mappings (EPMA), respectively, for the $\mathrm{Mn}+\mathrm{LiNH}_{2}$ sample treated at $1100^{\circ} \mathrm{C}$ for $2 \mathrm{~h}$ under $5 \mathrm{GPa}$. The dark phase in the BSE image is assumed to be due to BN dispersed by the FIB process during the sample fabrication. The composition ratio of the primary light phase was estimated to be $\mathrm{Mn}: \mathrm{N}=$ 2:1 from chemical composition analysis. B was not observed. Apart from $\mathrm{BN}$, the only unidentified phase apparent in this

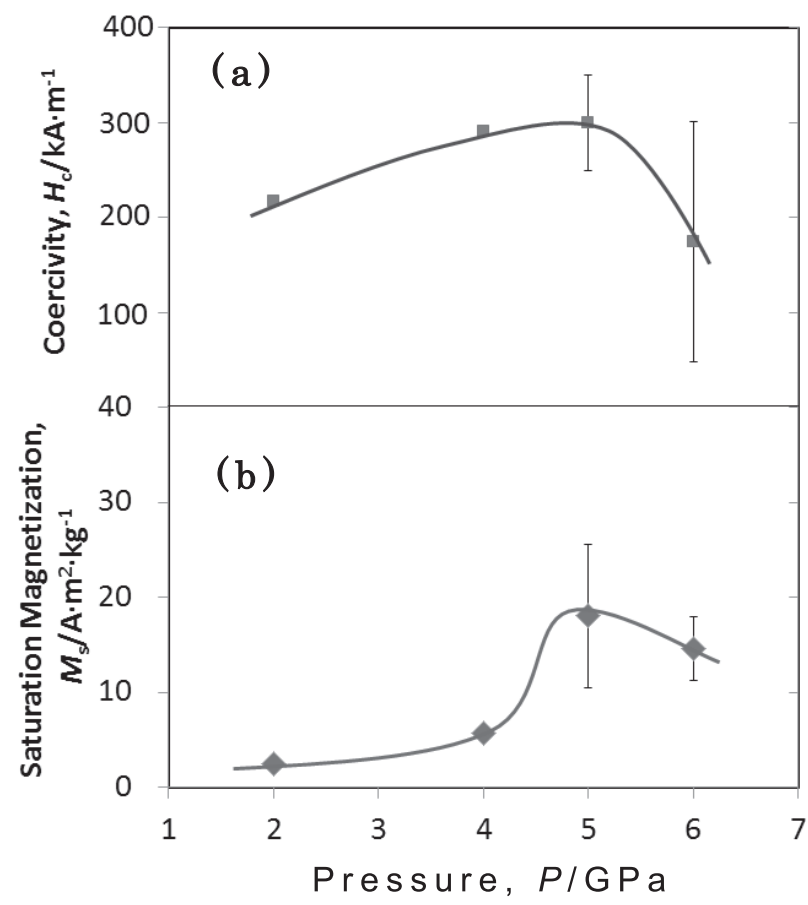

Fig. 2 Magnetic properties of $\mathrm{Mn}+\mathrm{LiNH}_{2}$ samples treated at $1100^{\circ} \mathrm{C}$ for $2 \mathrm{~h}$ under $P=2-6 \mathrm{GPa}$ (a) coercivity and (b) saturation magnetization.

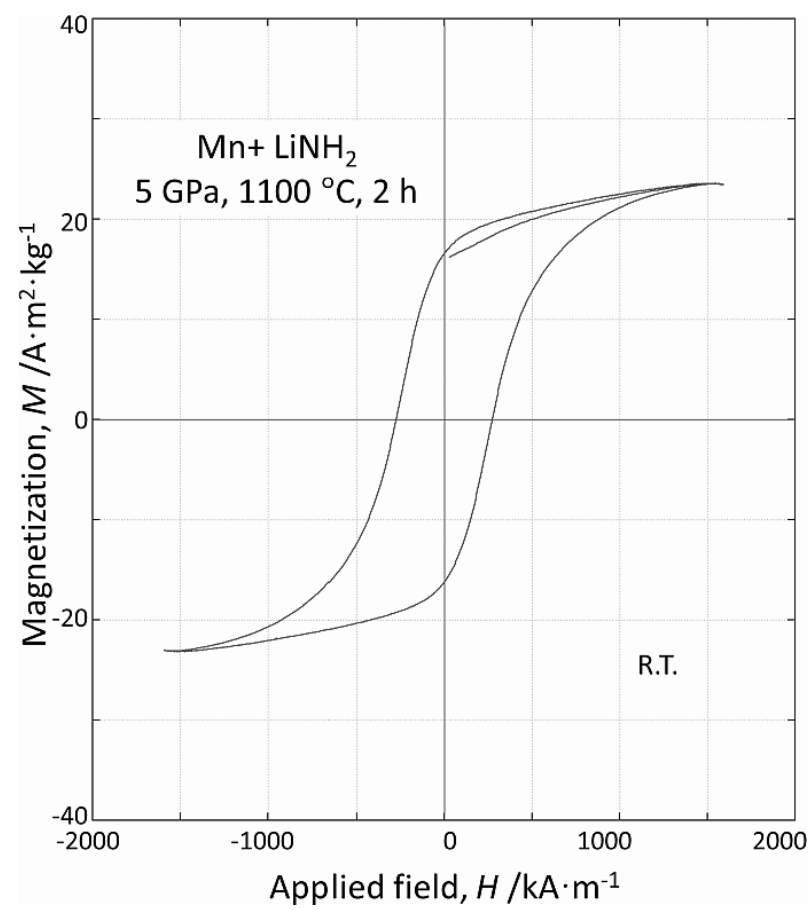

Fig. 3 Magnetization curve of $\mathrm{Mn}+\mathrm{LiNH}_{2}$ sample treated at $1100^{\circ} \mathrm{C}$ for $2 \mathrm{~h}$ under $P=5 \mathrm{GPa}$. 

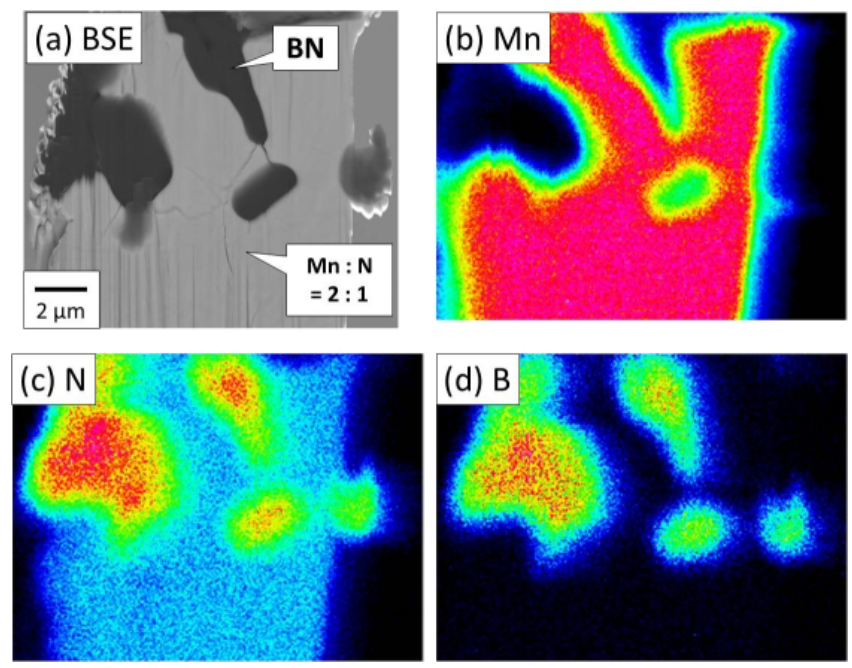

Fig. 4 EPMA images of $\mathrm{Mn}+\mathrm{LiNH}_{2}$ treated at $1100^{\circ} \mathrm{C}$ for $2 \mathrm{~h}$ under $P=$ $5 \mathrm{GPa}$. (a) Back-scattered electron (BSE) image and element mappings of (b) Mn, (c) N, and (d) B.

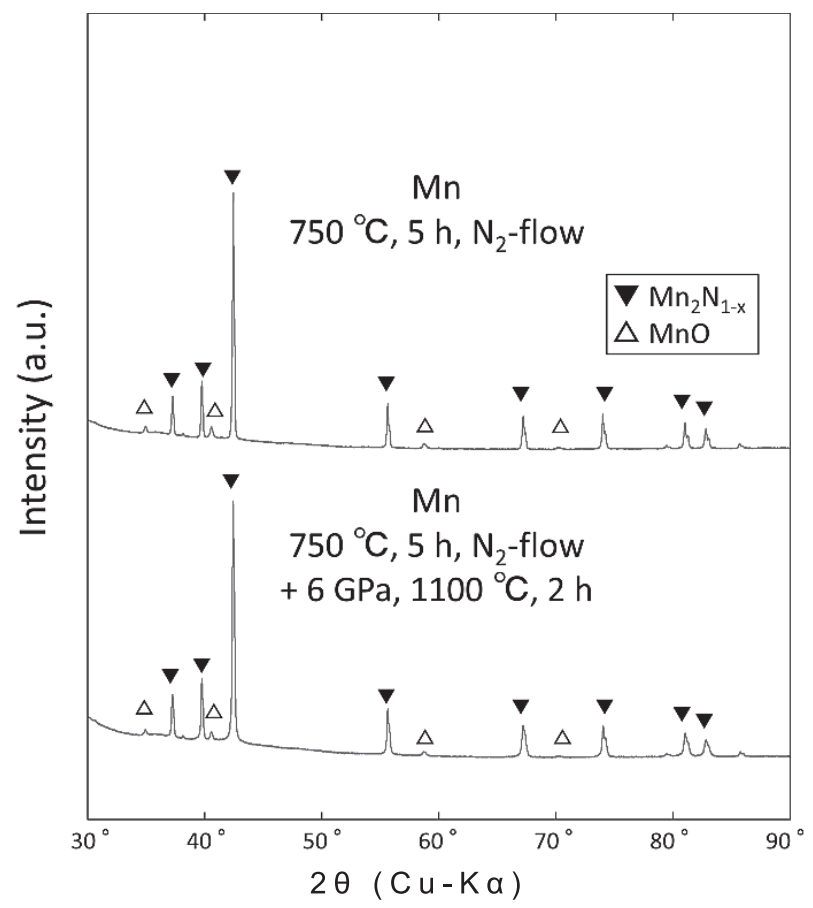

Fig. 5 XRD patterns of $\mathrm{Mn}_{2} \mathrm{~N}$ samples before and after high-pressure heat treatment at $1100^{\circ} \mathrm{C}$ for $2 \mathrm{~h}$ under $P=6 \mathrm{GPa}$.

image corresponds to that observed in the XRD results for this sample (Fig. 1). Therefore, the primary light phase can be taken as the unidentified phase, having a composition ratio of $\mathrm{Mn}: \mathrm{N}=2: 1$. Note, however, that EPMA analysis is unable to detect the presence of $\mathrm{Li}$, as this is a very light element.

Therefore, an Mn-N binary sample without Li was also synthesized, so as to confirm the presence of $\mathrm{Li}$ in the unidentified phase in a paradoxical manner. Figure 5 shows the XRD patterns of $\mathrm{Mn}_{2} \mathrm{~N}$ samples before and after high-pressure heat treatment at $1100^{\circ} \mathrm{C}$ for $2 \mathrm{~h}$ under $6 \mathrm{GPa}$. After this treatment, the $\mathrm{Mn}_{2} \mathrm{~N}_{1-\mathrm{x}}$ peaks remained and the unidentified phase was not observed; this was despite the fact that the Mn:N composition ratio in the sample was identical to that of the unidenti-

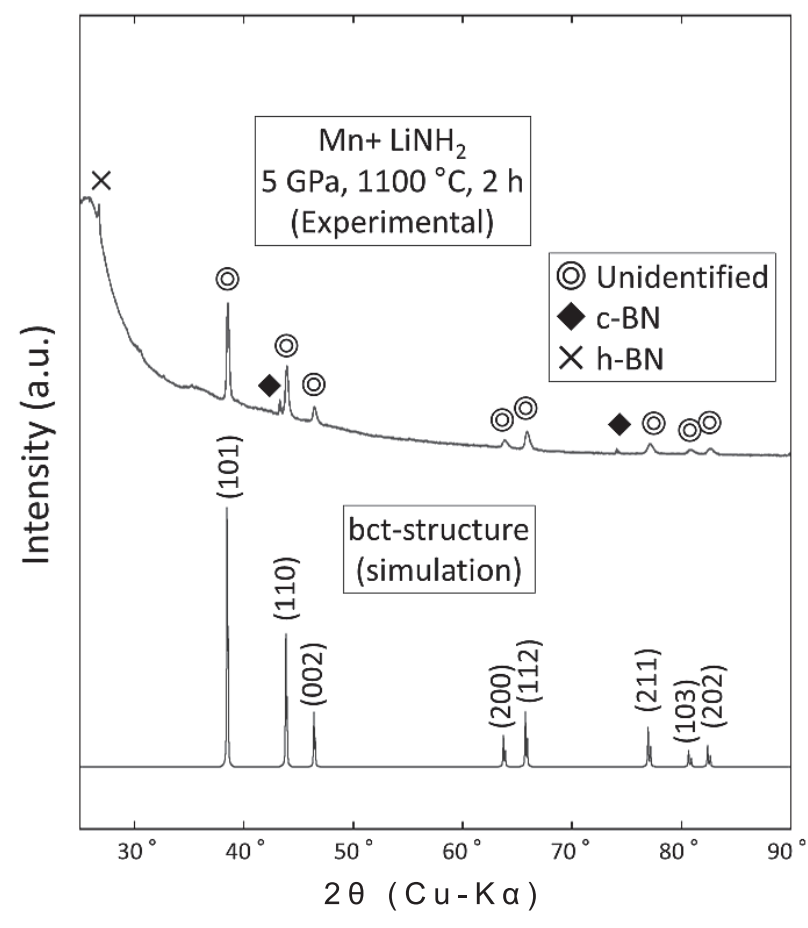

Fig. 6 XRD patterns of $\mathrm{Mn}+\mathrm{LiNH}_{2}$ treated at $1100^{\circ} \mathrm{C}$ for $2 \mathrm{~h}$ under $P=$ $5 \mathrm{GPa}$ and of simulated bct structure.

Table 1 Atomic positions and crystal structure of the bct structure.

\begin{tabular}{ccccc}
\multicolumn{5}{c}{ Space group: I4/mmm (No. 139) } \\
$\mathrm{a}=0.29186 \mathrm{~nm}$ \\
$\mathrm{c}=0.39108 \mathrm{~nm}$
\end{tabular}

fied phase, i.e., $\mathrm{Mn}: \mathrm{N}=2: 1$. As the unidentified phase was not synthesized without $\mathrm{Li}$, this element was therefore assumed to play a role in the formation of the unidentified phase.

The crystal structure of the unidentified phase in the Mn$\mathrm{Li}-\mathrm{N}$ system was then investigated. However, it was difficult to determine the Li content or position, because of this element's small atomic number. Therefore, the crystal structure was examined in the context of the $\mathrm{Mn}$ and $\mathrm{N}$ sublattices only. A body-centered-tetragonal (bct) structure (space group: I4/ mmm, No. 139) was suggested. Figure 6 shows the XRD patterns of both the 5-GPa sample and a simulated bet structure. The lattice constants of the bct structure were determined to be $a=0.29186 \mathrm{~nm}$ and $c=0.39108 \mathrm{~nm}$, and the simulated pattern exhibited good agreement with that of the 5-GPa sample. The atomic positions and crystal structure of the bct structure are shown in Table 1 and Fig. 7, respectively. The N occupancy was estimated by considering a composition ratio of $\mathrm{Mn}: \mathrm{N}=2: 1$. Note that Enoki and Ohtani ${ }^{18)}$ have estimated the crystal structure and magnetic properties of the bct compound using ab-initio calculations. Good agreement is obtained between the experimental results of the present study and the values calculated by Enoki and Ohtani ${ }^{18)}$, when the $\mathrm{N}$-site vacancies are located in the center of c-plane. They also suggested that some Li-atoms might be substituted a part 


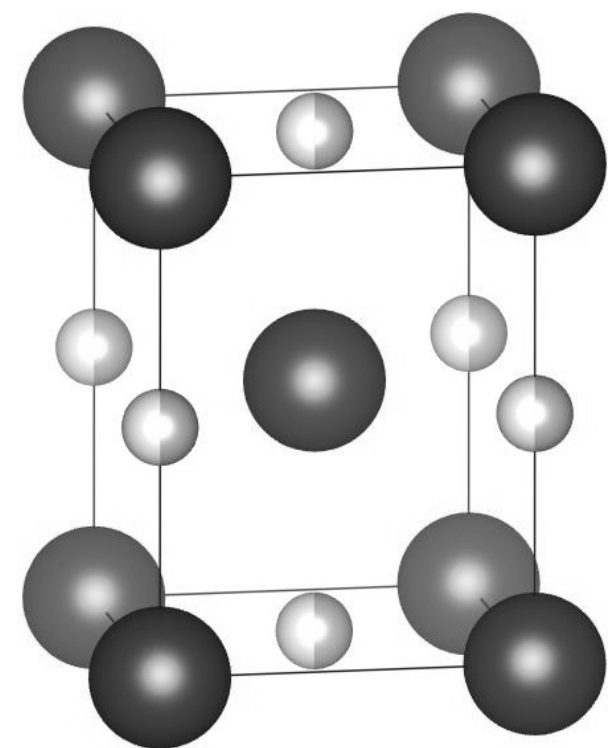

Fig. 7 Suggested crystal structure of $\mathrm{Mn}-\mathrm{Li}-\mathrm{N}$ bct phase.

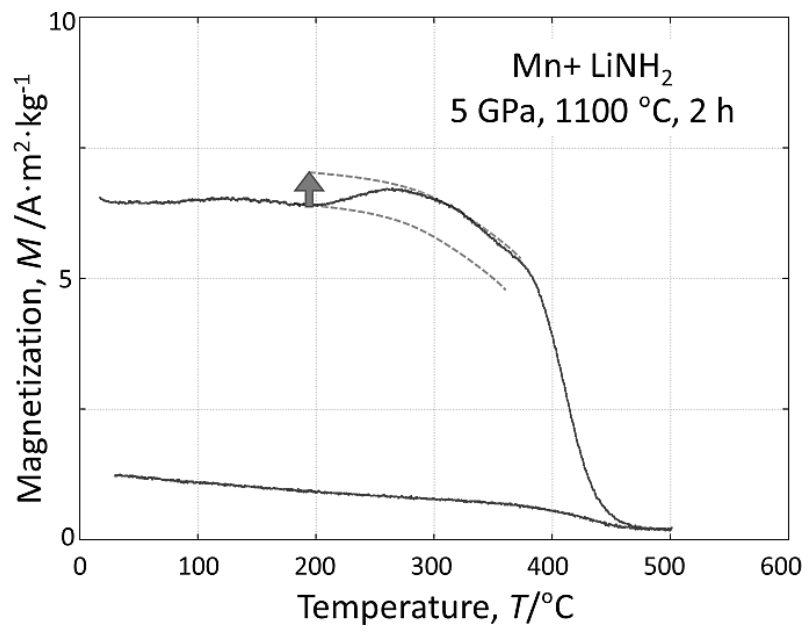

Fig. 8 Thermomagnetization curve of $\mathrm{Mn}+\mathrm{LiNH}_{2}$ treated at $1100^{\circ} \mathrm{C}$ for $2 \mathrm{~h}$ under $5 \mathrm{GPa}$.

of Mn-sites.

The composition ratio of the new bct phase, $\mathrm{Mn}: \mathrm{N}=2: 1$, is similar to that of the $\zeta$-phase $\left(\mathrm{Mn}_{2} \mathrm{~N}_{1-\mathrm{x}}\right)$ in the $\mathrm{Mn}-\mathrm{N}$ binary system. However, the crystal structure of the new bct phase differs from that of the $\zeta$-phase, which has a hexagonal structure. Therefore, the bct phase is thought to differ from the $\zeta$ phase. Further, the crystal structures of the new bct phase and the other $\mathrm{Mn}-\mathrm{N}$ binary compounds, $\mathrm{Mn}_{4} \mathrm{~N}, \mathrm{Mn}_{3} \mathrm{~N}_{2}$ and $\mathrm{MnN}$, are similar; however, their lattice constants or $\mathrm{N}$ content values differ slightly. Through consideration of the magnetic properties, the new bct phase is assumed to be ferro- or ferrimagnetic. Note that $\mathrm{Mn}_{4} \mathrm{~N}$ is ferrimagnetic, while the $\zeta-$ phase, $\mathrm{Mn}_{3} \mathrm{~N}_{2}$, and $\mathrm{MnN}$ are antiferromagnetic at room temperature. The different lattice constants or the presence of $\mathrm{Li}$ may induce the magnetism of the bct phase.

The thermal stability of the bct phase was also investigated, and Fig. 8 shows the thermomagnetization curve of the 5-GPa sample. The sample magnetization increased slightly above $200^{\circ} \mathrm{C}$ during the heating process, but almost disappeared at

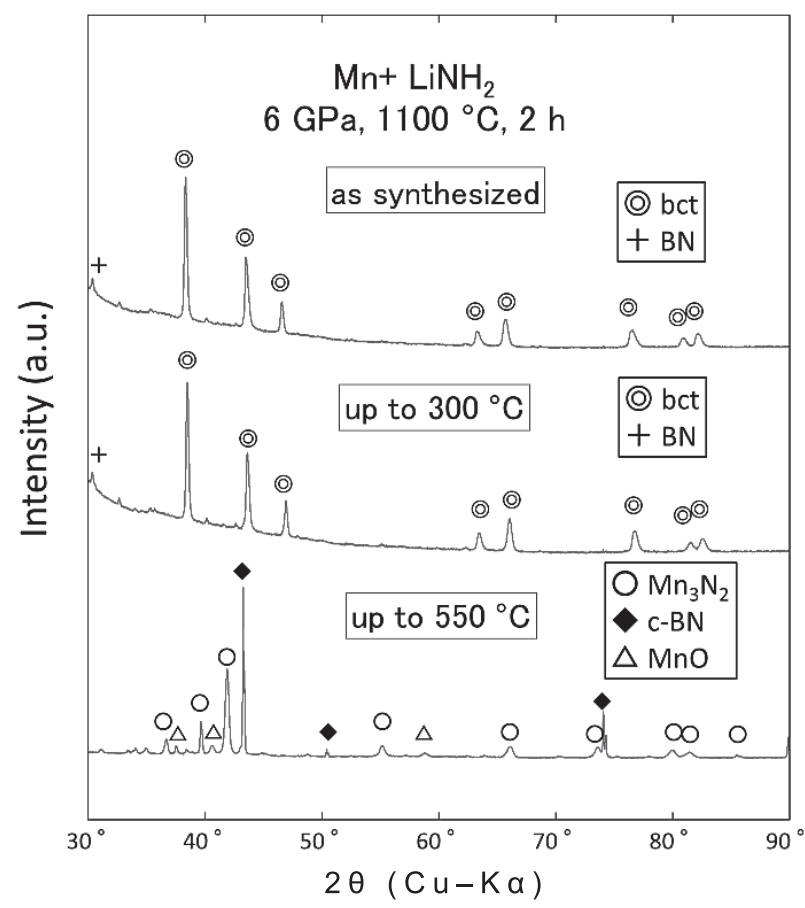

Fig. 9 XRD patterns of $\mathrm{Mn}+\mathrm{LiNH}_{2}$ treated at $1100^{\circ} \mathrm{C}$ for $2 \mathrm{~h}$ under $P=$ $5 \mathrm{GPa}$ before heat treatment, and after heat treatment up to 300 and $500^{\circ} \mathrm{C}$.

approximately $465^{\circ} \mathrm{C}$. This value corresponds to the Curie temperature of $\mathrm{Mn}_{4} \mathrm{~N}$. Finally, Fig. 9 shows the XRD patterns of 5-GPa samples before and after heat treatment up to 300 and $550^{\circ} \mathrm{C}$ under atmospheric pressure. The samples were heated at a rate of $10^{\circ} \mathrm{C} / \mathrm{min}$. The bct peaks remained present after heating to $300^{\circ} \mathrm{C}$, but the $a$ and $c$ values in the bct-phase changed from 0.29186 to $0.29299 \mathrm{~nm}$ and from 0.39108 to $0.38697 \mathrm{~nm}$, respectively. Judging from this result, the small magnetization increment at $\sim 200^{\circ} \mathrm{C}$ (Fig. 8) would be due to the changes in the bct-phase lattice parameters. After heating to $550^{\circ} \mathrm{C}, \mathrm{Mn}_{3} \mathrm{~N}_{2}, \mathrm{MnO}$, and c- $\mathrm{BN}$ were primarily observed.

\section{Conclusion}

A new compound was synthesized from $\mathrm{Mn}$ and $\mathrm{LiNH}_{2}$ using a high pressure of $5 \mathrm{GPa}$, at a temperature of $1100^{\circ} \mathrm{C}$ and for $2 \mathrm{~h}$. The new phase had a bct structure (space group: $I 4 / \mathrm{mmm}$, No. 139) with $a=0.29186 \mathrm{~nm}$ and $c=0.39108 \mathrm{~nm}$. The 5-GPa sample exhibited coercivity and saturation magnetization of approximately $310.7 \mathrm{kA} / \mathrm{m}$ and $17.7 \mathrm{~A} \cdot \mathrm{m}^{2} / \mathrm{kg}$, respectively. The bct phase composition ratio was $\mathrm{Mn}: \mathrm{N}=$ $2: 1$. It was found that $\mathrm{Li}$ plays a role in the formation of the bct phase, because this phase was not observed to develop from an $\mathrm{Mn}-\mathrm{N}$ binary system. Precursor consisting $\mathrm{LiNH}_{2}$ for high-pressure synthesis was fount to be effective to explore new magnetic compound in Li systems.

\section{Acknowledgments}

This work was partly supported by the Japan Core Research for Evolutionary Science and Technology (CREST) project and Precursory Research for Embryonic Science and Technology (PRESTO) under the Japan Science and Technol- 
ogy Agency (JST).

\section{REFERENCES}

1) K. Suzuki, X. Wu, V. Ly, T. Shoji, A. Kato, A. Manabe: J. Appl. Phys. 111 (2012) 07E303-07E303.

2) E. Fazakas, L. Varga and F. Mazaleyrat: J. Alloy. Compd. 434-435 (2007) 611-613.

3) B. Balke, G.H. Fecher, J. Winterlik and C. Felser: Appl. Phys. Lett. 90 (2007) 152504

4) F. Wu, S. Mizukami, D. Watanabe, H. Naganuma, M. Oogane, Y. Ando and T. Miyazaki: Appl. Phys. Lett. 94 (2009) 122503.

5) N. Yamada, H. Sakai, H. Mori, T. Ohoyama: Physica B+C, 149 (1988) 311-315.

6) A.F. Andresen, W. Halg, P. Fischer and E. Stoll: Acta Chem. Scand. 21 (1967) 1543-1554.

7) I. Obinata, Y. Takeuchi, K. Kurihara and M. Watanabe: J. Japan Inst. Metals 28 (1964) 562-568.
8) S. Minomura: "High Pressure", (in Japanese) (1988) 760-770

9) T.B. Massalski: "Binary alloy phase diagrams", Vol. 3 (1990) 25732578.

10) C. Li, Y. Yang, L. Lv, H. Huang, Z. Wang and S. Yang: J. Alloy. Compd. 457 (2008) 57-60.

11) G. Kreiner and H. Jacobs: J. Alloy. Compd. 183 (1992) 345-362.

12) K. Suzuki, T. Kaneko, H. Yoshida, Y. Obi, H. Fujimori and H. Morita: J. Alloy. Compd. 306 (2000) 66-71.

13) Z. Sun and X. Song: Mater. Lett. 63 (2009) 2059-2062.

14) A. Kamegawa, Y. Goto, H. Kakuta, H. Takamura and M. Okada: J. Alloy. Compd. 408-412 (2006) 284-287.

15) M. Ohta, M. Okada, H. Kakuta, A. Fujita, K. Fukamichi, A. Kamegawa, H. Takamura and M. Okada: J. Alloy. Compd. 408-412 (2006) 147-150.

16) A. Kamegawa, Y. Goto, R. Kataoka, H. Takamura and M. Okada: Renew. Energy 33 (2008) 221-225.

17) D. Yang, X. Ji, H. Liu, Y. Li, T. Zhang and P. Zhu: Diamond Related Materials 20 (2011) 174-177.

18) K. Enoki, H. Ohtani (2016), to be submitted. 